\title{
PRÁTICAS PEDAGÓGICAS MEDIADAS POR TECNOLOGIAS DIGITAIS EM PERÍODO DE PANDEMIA
}

Maria Claudice Rocha Almeida ${ }^{1}$

\section{RESUMO}

Este artigo relata experiências pedagógicas remotas desenvolvidas na disciplina "Educação em Espaços não Escolares", do curso de Licenciatura em Pedagogia da Faculdade Dom Pedro II de Sergipe. Essas aulas foram decorrentes da suspensão das aulas presenciais, devido à pandemia do novo coronavírus (Sars-CoV-2), causador da doença COVID-19. Focalizam-se práticas de ensino no Google Classroom e no Google Meet, inspiradas no desenvolvimento de operações mentais, baseadas na dialética e nas metodologias ativas da aprendizagem. Entre os resultados, podem-se destacar as significativas aprendizagens da professora e dos estudantes, os quais tiveram de se adequar a uma nova realidade não dimensionada. Os estudantes, fluentes digitais, apesar dos problemas de conexão com a internet, não obtiveram prejuízos cognitivos. Pode-se inferir, portanto, que houve tentativas de replicar o ensino presencial, porém as limitações da professora no tocante à utilização ampla das Tecnologias Digitais da Informação e Comunicação (TDIC) ensejaram reflexões para melhoria das práticas futuras.

Palavras-chave: Aulas remotas. Ensino de Pedagogia. Metodologias ativas. Plataformas digitais.

\section{Como citar este documento - ABNT}

ALMEIDA, Maria Claudice Rocha. Práticas pedagógicas mediadas por tecnologias digitais em período de pandemia. Revista Docência do Ensino Superior, Belo Horizonte, v. 10, e024827, p. 1-20, 2020. DOI: https://doi.org/10.35699/22375864.2020.24827.

Recebido em: 03/09/2020 Aprovado em: 09/11/2020 Publicado em: $12 / 12 / 2020$

\footnotetext{
${ }^{1}$ Faculdade Dom Pedro II de Sergipe, Lagarto, SE, Brasil.

ORCID: https://orcid.org/0000-0001-7880-3186. E-mail: maria.almeida@unidompedro.com.
} 


\section{PRÁCTICAS PEDAGÓGICAS MEDIADAS POR LAS TECNOLOGÍAS DIGITALES EN EL PERÍODO DE PANDEMIA}

\section{RESUMEN}

Este artículo relata las experiencias pedagógicas remotas desarrolladas en la asignatura "Educación en Espacios no Escolares", de la carrera de Pedagogía del Colegio Dom Pedro II del estado de Sergipe. Estas clases son el resultado de la suspensión de clases presenciales debido a la pandemia del nuevo coronavirus (Sars-CoV-2), que causa la enfermedad COVID19. Se centran las prácticas docentes en Google Classroom y Google Meet, inspiradas en el desarrollo de operaciones mentales, basadas en dialécticas y metodologías de aprendizaje activo. Entre los resultados podemos destacar el aprendizaje significativo de la docente y de los estudiantes, quienes debieron adaptarse a una nueva realidad no dimensionada. Los estudiantes, con fluidez digital, a pesar de los problemas de conexión a internet, no obtuvieron deterioros cognitivos. Se puede inferir, por tanto, que hubo intentos de replicar la enseñanza presencial, pero las limitaciones de la docente en cuanto al amplio uso de las Tecnologías Digitales de Información y Comunicación (TDIC) llevaron a reflexiones para mejorar prácticas futuras.

Palabras clave: Clases remotas. Didáctica de la Pedagogía. Metodologías activas. Plataformas digitales.

\section{PEDAGOGICAL PRACTICES MEDIATED BY DIGITAL TECHNOLOGIES IN THE PANDEMIC PERIOD}

\section{ABSTRACT}

This article reports remote pedagogical experiences developed in the discipline "Education in Non-School Spaces", of the Pedagogy Degree course at Faculdade Dom Pedro II of Sergipe. These classes resulted from the suspension of face-to-face classes due to the pandemic of the new coronavirus (Sars-CoV-2), which causes COVID-19 disease. The paper focuses on teaching practices at Google Classroom and Google Meet, inspired by the development of mental operations, based on dialectics and active learning methodologies. Among the results, we can highlight the significant learning of the teacher and the students, who had to adapt to a new reality that was not dimensioned. The students, "digital fluent people", despite the problems with internet connection, did not obtain cognitive impairments. It can be inferred, therefore, that there were attempts to replicate face-to-face teaching, but the teacher's limitations regarding the wide use of Digital Technologies of Information and Communication (DTIC) led to reflections to improve future practices.

Keywords: Remote classes. Pedagogy teaching. Active methodologies. Digital platforms. 


\section{INTRODUÇÃO}

Há algum tempo, as Tecnologias Digitais da Informação e Comunicação (TDIC) foram incorporadas no desenvolvimento do repertório metodológico das aulas presenciais e a distância no ensino superior. A utilização dessas mídias integra professores e estudantes de modo síncrono e assíncrono, como previsto por Lévy (1999), construindo uma cibercultura educacional.

Surpreendidos pela pandemia de SARS-CoV-2, popularmente conhecido como novo coronavírus, os professores foram desafiados a transformarem suas práticas pedagógicas presenciais em aulas remotas, autorizadas pelo Ministério da Educação e Cultura (MEC), por meio da Portaria no 343 de 17 de março de 2020, uma vez que as atividades presenciais foram suspensas. Para tanto, na urgência e na incerteza emocional, as professoras tiveram que mobilizar os conhecimentos para criar e gerir Ambientes Virtuais de Aprendizagem (AVA) e usar outras tecnologias digitais que resultassem em efetivas aprendizagens. "Ensinar com as novas mídias será uma revolução se mudarmos simultaneamente os paradigmas convencionais do ensino, que mantêm distantes professores e estudantes. Caso contrário, conseguiremos dar um verniz de modernidade, sem mexer no essencial" (MORAN, 2000, p. 63).

O autor esclarece a necessidade de mudança dos paradigmas, pois não adianta incorporar novas mídias e continuar utilizando metodologias centradas na transmissão de conhecimentos. Diante desse desafio, surgiram as seguintes inquietações: quais plataformas digitais seriam mais adequadas para a construção de um AVA, de modo a favorecer a interação entre professora e discentes e possibilitar à professora a organização do material para leitura, encaminhar atividades, fazer a devolutiva, controlar a frequência e realizar as avaliações formativas e somativas? Como garantir efetivas aprendizagens nas aulas, nessa integração de conteúdos curriculares e tecnologias digitais da informação e comunicação? Quais práticas pedagógicas poderão atender as intencionalidades da disciplina na busca de desenvolver a progressão das operações mentais?

Na busca de respostas a essas indagações, buscaram-se as contribuições de Anastasiou e Alves (2015), Bastos (2006), Freire (2010), Lévy (1999), Moran (2000, 2003, 2018), Moran et al. (2007) e Tardif e Lessard (2011), além da leitura de tutoriais da Instituição, do Google e de Universidades como Universidade de São Paulo (USP), Universidade Estadual Paulista (UNESP) e Universidade Federal de São Carlos (UFSCar).

Objetiva-se, portanto, apresentar um relato de práticas de ensino remoto desenvolvidas no primeiro semestre de 2020, com 31 estudantes do sétimo período do curso de Licenciatura em Pedagogia, especificadamente, na disciplina "Educação em Espaços não Escolares", da Faculdade Dom Pedro II de Sergipe, pertencente ao grupo UNIDOM (Universidade Dom 
Pedro II, com sede em Salvador). Espera-se ainda, contribuir com o desenvolvimento de práticas pedagógicas remotas mediadas pelas TDIC.

O desenvolvimento deste artigo está estruturado em três seções: na primeira, discutiu-se sobre a disciplina "Educação em Espaços não Escolares" no contexto do curso de Pedagogia; na segunda, abordaram-se reflexões das plataformas digitais utilizadas nas aulas remotas; e, por fim, apresentou-se uma abordagem sobre o relato da experiência, subdividida em uma subseção que discute sobre o ensino, a aprendizagem e a avaliação das aulas remotas.

\section{A DISCIPLINA “EDUCAÇÃO EM ESPAÇOS NÃO ESCOLARES" NO CURSO DE LICENCIATURA EM PEDAGOGIA}

A entrada da disciplina nos currículos de formação de professores se configurou a partir da Resolução do CNE/CP № 1 de 15 de maio de 2006, art. 4으, ao estabelecer que:

O curso de Licenciatura em Pedagogia destina-se a formação de professores para atuar na Educação Infantil, nos anos iniciais do Ensino Fundamental, nos cursos de Ensino Médio na Modalidade Normal, de Educação Profissional na área de serviços e apoio escolar e em outras áreas nas quais exijam conhecimentos pedagógicos (BRASIL, 2006, p. 2).

Além disso, vale destacar alguns incisos do artigo 5으 da mesma resolução, os quais versam que o egresso deve estar apto a:

IV - Trabalhar, em espaços escolares e não-escolares, na promoção da aprendizagem de sujeitos em diferentes fases do desenvolvimento humano, em diversos níveis e modalidades do processo educativo;

XIII - Participar da gestão das instituições planejando, executando, acompanhando e avaliando projetos e programas educacionais, em ambientes escolares e não-escolares;

XIV - Realizar pesquisas que proporcionem conhecimentos, entre outros: sobre estudantes e alunas e a realidade sociocultural em que estes desenvolvem suas experiências não escolares; sobre processos de ensinar e de aprender, em diferentes meios ambiental-ecológicos; sobre propostas curriculares; e sobre organização do trabalho educativo e práticas pedagógicas. (BRASIL, 2006, p. 2-3).

Assim concebida, a formação no curso de Pedagogia desafia os estudantes na obtenção de conhecimentos do campo educacional, na área da docência e em funções pedagógicas em órgãos de planejamentos, gestão, projetos de pesquisa, acompanhamento e avaliação dos processos educacionais em espaços escolares e não escolares. Desse modo, a disciplina em questão integra os fundamentos teórico-práticos do curso de Licenciatura em Pedagogia, com o objetivo de ampliar e fortalecer atitudes éticas, competências e habilidades dos futuros profissionais para atuação em espaços que exijam conhecimentos pedagógicos. 


\section{USO DE PLATAFORMAS COLABORATIVAS DE AULAS REMOTAS}

A sociedade atual foi impactada pela acelerada disseminação da COVID-19, e os crescentes problemas sociais exigiram transformações no convívio social, na economia e, consequentemente, na educação. Face à multiplicidade de demandas, os professores precisaram, com rapidez e criatividade, encontrar alternativas para o prosseguimento do trabalho iniciado, com o compromisso de oferecer, nas linguagens digitais, experiências pedagógicas que envolvessem os educandos de modo que se conseguisse alcançar os resultados esperados, ou seja, qualidade na aprendizagem.

Vale ressaltar que a acelerada expansão tecnológica proporciona inúmeras plataformas digitais para diversos campos do conhecimento. Têm-se plataformas voltadas para educação de iniciativa pública e/ou privada disponíveis nas instituições de ensino, nos centros universitários e nas faculdades; e plataformas utilizadas pelos estudantes e professores nas suas relações interpessoais. Assim, existem as plataformas oficiais adquiridas e geridas pelas instituições de ensino e as plataformas de uso social. Ambas oferecem suportes aos professores e discentes com as aprendizagens, principalmente no ensino superior, já que os estudantes são mais autônomos.

Nesse cenário, a Faculdade Dom Pedro II de Sergipe oferece, conforme as diretrizes educacionais, $40 \%$ de sua carga horária de disciplinas de educação a distância, denominada de Presencial Educação a Distância (PEAD).

Desse modo, os professores e estudantes dessa instituição de ensino já estão imersos nas tecnologias digitais por meio do sistema PEAD, da biblioteca digital consorciada com a instituição acessada por meio de smartphones, tablets e computadores, além dos serviços das mídias sociais (Google, Facebook, Instagram, YouTube, WhatsApp etc.). Há uma variedade de plataformas e mídias que auxiliam o trabalho pedagógico nas disciplinas presenciais e nas disciplinas a distância, o que contribui para metodologias ativas e modelos híbridos de educação, pois inserem processos mais flexíveis, digitais, dinâmicos e diversificados.

Metodologias ativas são estratégias de ensino centradas na participação efetiva dos estudantes na construção do processo de aprendizagem, de forma flexível, interligada, híbrida. As metodologias ativas num mundo conectado e digital se expressam através de modelos de ensino híbridos, com muitas possíveis combinações. A junção de metodologias ativas com modelos flexíveis, híbridos traz contribuições importantes para o desenho de soluções atuais para os aprendizes de hoje (MORAN, 2018, p. 2).

Nessa perspectiva, nota-se que os estudos híbridos, com momentos presenciais e outros a distância, foram substituídos por estratégias interativas de aprendizagem, conectadas às tecnologias digitais para realização de diferentes atividades mediadas pela professora. Assim 
possibilitou-se a progressão das habilidades cognitivas por meio dos conteúdos (conceituais, procedimentais e atitudinais) e dos socioemocionais (motivação, empatia, autoconfiança, resiliência, autocontrole, adaptabilidade e criatividade), habilidades fundamentais para saúde emocional, principalmente em um período de pandemia.

Ainda com relação às metodologias ativas, Bastos (2006, p. 10) as conceitua como "processos interativos de conhecimento, análise, estudos, pesquisas e decisões individuais ou coletivas, com a finalidade de encontrar soluções para um problema". Nesse processo, o professor atua como orientador das atividades para que o estudante faça análises, elabore projetos, estude casos e resolva situações problemas.

Corroborando com Bastos (2006), no que diz respeito à interatividade, Tardif e Lessard (2011, p. 235) defendem ser essencial no trabalho do professor. Para os autores, "ensinar é um trabalho interativo", porque permite ao professor, ao sugerir uma atividade e/ou realizar uma transposição didática, ler e interpretar os olhares, as motivações, as compreensões, os absenteísmos, as inserções na atividade e, na imediatez dos acontecimentos, fazer a regulação necessária.

Apesar de as aulas remotas não oferecerem condições adequadas para um trabalho interativo, como proposto pelos autores, elas precisavam se desenvolver com interatividade, motivação e responsabilidade para atender não só às expectativas e necessidades dos estudantes, como também aos propósitos dos conteúdos curriculares expressos no planejamento da disciplina. Desse modo, urgiu a necessidade de uma plataforma que permitisse a professores e estudantes a conectividade com boa qualidade de voz, boa imagem de texto, nos dias e horários das aulas presenciais, a partir das suas residências, para participação interativa.

Escolhida a plataforma, iniciaram-se as aulas que serão sistematizadas abaixo, mediante uma descrição intersubjetiva da autora da própria cena, acerca dos atos e fatos que compuseram o semestre letivo, na tentativa de, nas aulas remotas, dar conta da tríade ensino, pesquisa e extensão no ensino superior.

\section{RELATO DE EXPERIÊNCIAS NA DISCIPLINA “EDUCAÇÃO EM ESPAÇOS NÃO ESCOLARES”}

As aulas presenciais iniciaram em fevereiro de 2020, momento em que fora apresentado e discutido o Plano de Ensino inspirado no método dialético, com foco no desenvolvimento de operações mentais e nas metodologias ativas de aprendizagem. Durante a apresentação, a professora explicitou os conteúdos, as estratégias, os instrumentos de avaliação formativa e somativa e as referências. Na especificação das estratégias, o Plano de Ensino contemplou: exposição didática dialogada, pesquisas de campo, desenvolvimento de projetos, produção e socialização de vídeos, estudos de caso, elaboração de resumos, fichamentos, análises de 
filmes e vídeos, estudos dirigidos e questionários. Na oportunidade, registrou-se que a disciplina iria oferecer suporte teórico e prático ao Estágio Supervisionado em Educação Não Escolar. Os estudantes demonstraram entusiasmo para os estudos planejados, tiraram as dúvidas e ofereceram sugestões de projetos que poderiam ser desenvolvidos na comunidade, numa ação integrada entre as duas disciplinas.

No entanto, na segunda semana do mês de março do corrente ano, o município decretou medidas de isolamento social e as aulas presenciais foram substituídas por aulas remotas. Nesse momento, a instituição de ensino superior informou que criaria uma sala de aula no AVA do Google para todas as turmas da instituição. Então, a instituição sinalizou o uso da plataforma Google G. Suitte for Education, que permitia conectividade em tempo real, podendo ser acessada por várias mídias e com possibilidade de estruturar os conteúdos de modo a estimular ao máximo o potencial cognitivo dos estudantes. Tal fato trouxe à tona a definição das TDIC de Almeida e Valente (2012), como produtos da convergência de várias mídias e tecnologias entre si em um só instrumento (vídeo, computador, tablet, celular, jogos digitais, câmeras digitais, calculadoras etc.). A partir disso, no replanejamento foi preciso pensar nos aspectos cognitivos e afetivos dos discentes e nas dificuldades do acesso à biblioteca física da instituição, frente a uma realidade não pensada pela sociedade e pela comunidade acadêmica, já que estava se iniciando o período de isolamento social, o qual não se sabia por quanto tempo duraria.

Enquanto aguardava a Sala de Aula oficial, a professora, num processo de autoformação, montou uma turma no AVA do Google Classroom (Sala de Aula) com a postagem dos conteúdos curriculares, slides e atividades da Unidade I. Devido à insegurança na utilização do Hangout, a professora escolheu o aplicativo Skype para as interlocuções iniciais, usando também o aplicativo WhatsApp.

No mês de abril, a faculdade criou uma sala no Google G. Suitte for Education (plataforma educacional colaborativa que pode ser acessada do computador ou celular e disponibiliza um conjunto de ferramentas, sendo que as utilizadas nas atividades pedagógicas dessa disciplina foram: Google Classroom, Google Agenda, Google Meet, Google Slide, Google Fotos e Google Docs). A partir desse momento, os conteúdos e atividades anteriores postadas no Google Classroom foram transferidos e complementados para essa nova sala de aula oficial, organizada conforme o modelo da referida plataforma (Mural, Atividades, Pessoas e Notas) e as aulas presenciais foram ministradas por meio de videoconferências pelo Google Meet.

Nas Atividades, foram criados e disponibilizados espaços para apresentação da disciplina, comunicados e avisos, plano de ensino, conteúdos, instrumentos de avaliação e material complementar, organizados nas unidades de aprendizagem. Vale ressaltar ainda que, nas unidades de aprendizagem, foram anexados, de acordo com o plano de ensino, livros em 
formato PDF referentes aos conteúdos, artigos científicos, slides, textos produzidos pela professora, bem como links de vídeos, filmes e documentários.

Consoante ao Projeto Pedagógico do Curso de Licenciatura em Pedagogia, a disciplina faz parte do sétimo período, com carga horária de 70 horas/aula, sendo $60 \mathrm{~h}$ de fundamentos teóricos e $10 \mathrm{~h}$ de prática pedagógica, distribuídas em 3 aulas semanais. Porém, para compensar os feriados e assim cumprir a sua carga horária, em algumas semanas foram inseridos sábados letivos.

Nos três quadros abaixo, serão apresentadas sínteses das operações mentais, conteúdos, autores e estratégias didáticas desenvolvidas nas aulas presenciais e nas remotas. O número de aulas está representado pela simbologia A e sua sequência, $1,2,3 \ldots$, até perfazer as 70 horas/aula da disciplina.

\begin{tabular}{|l|l|l|}
\hline Operação Mental & \multicolumn{1}{|c|}{$\begin{array}{c}\text { No de Aulas/ } \\
\text { Conteúdos }\end{array}$} & \multicolumn{1}{|c|}{ Atividades propostas para os estudantes } \\
\hline Comparação & A1 a A3 & $\begin{array}{l}\text { Leitura da poesia "Aprendizagem". Entrega de } \\
\text { questionário para levantamento das concepções iniciais } \\
\text { sobre aprendizagem, conceito de educação comparação } \\
\text { das percepções dos estudantes com os conceitos } \\
\text { expressos na poesia e Lei de Diretrizes e Bases da } \\
\text { educação. } \\
\text { Educação Nacional (LDBEN). } \\
\text { Exibição do Plano de Ensino por meio de slides com } \\
\text { explicaçães acerca dos objetivos da disciplina, conteúdos } \\
\text { por unidades, estratégias de ensino, instrumentos de } \\
\text { avaliação e bibliografias, seguida de solicitação dos } \\
\text { posicionamentos e sugestões dos estudantes para possível } \\
\text { reestruturação. } \\
\text { Tarefa extra: leitura do livro de Gohn, Educação Não- } \\
\text { formal e Cultura Política: impactos sobre o associativismo } \\
\text { do 3o Setor, São Paulo: Cortez, 2011, identificando os } \\
\text { conceitos de cultura. }\end{array}$ \\
\hline Identificação/ \\
Classificação & $\begin{array}{l}\text { A3 a A5 } \\
\text { Os Conceitos de } \\
\text { Cultura, Cultura } \\
\text { Política e Cultura de } \\
\text { Massa. }\end{array}$ & $\begin{array}{l}\text { Devolutiva do questionário pelos estudantes e } \\
\text { apresentação dos conceitos de cultura identificados no } \\
\text { livro, mediados por questionamentos da professora. Em } \\
\text { seguida, exposição didática dialogada, por meio de slides, } \\
\text { dos conceitos de cultura com visionamento de vídeos e } \\
\text { simulação oral de situaçães sociais que representam os } \\
\text { conceitos de cultura trabalhados para os estudantes } \\
\text { classificarem os diferentes conceitos. } \\
\text { Tarefa extra: continuação da leitura do referido livro e } \\
\text { identificação os conceitos de primeiro setor, segundo } \\
\text { setor, terceiro setor, educação formal, informal e não } \\
\text { formal. }\end{array}$ \\
\hline
\end{tabular}




\begin{tabular}{|c|c|c|}
\hline $\begin{array}{l}\text { Identificação/ } \\
\text { Comparação }\end{array}$ & $\begin{array}{l}\text { A6 a A9 } \\
\text { Educação Informal, } \\
\text { Formal e Educação } \\
\text { Não Formal. }\end{array}$ & $\begin{array}{l}\text { Acolhida, seguida de solicitação aos estudantes da } \\
\text { apresentação dos conceitos de: primeiro setor, segundo } \\
\text { setor, terceiro setor, educação formal, informal e não } \\
\text { formal, mediados por questionamentos da professora. } \\
\text { Exposição didática dialogada, por meio de slides, sobre } \\
\text { educação em espaços não escolares. } \\
\text { Explicações acerca das avaliações formativas para a } \\
\text { Unidade I- Questionário, Resumo e Fichamento do livro } \\
\text { de Gohn (2011). } \\
\text { Tarefa extra: comentário sobre a ideia defendida por Gohn } \\
\text { (2006), "a articulação da educação formal com a não- } \\
\text { formal para dar vida e viabilizar mudanças significativas na } \\
\text { educação e na sociedade como um todo". }\end{array}$ \\
\hline
\end{tabular}

Quadro 1 - Operação mental, textos e atividades desenvolvidos em 9 aulas presenciais, iniciadas no dia 27 de fevereiro de 2020

Fonte: elaborado pela autora (2020).

\begin{tabular}{|c|c|c|}
\hline Operação Mental & $\begin{array}{c}\text { № de } \\
\text { Aulas/Conteúdos }\end{array}$ & Atividades propostas para os estudantes \\
\hline $\begin{array}{l}\text { Analisar/Resumir/ } \\
\text { Sintetizar }\end{array}$ & $\begin{array}{l}\text { A10 a A15 } \\
\text { Educação Não } \\
\text { Formal. }\end{array}$ & $\begin{array}{l}\text { Acolhimento e solicitação aos estudantes que exponham } \\
\text { suas respostas acerca das relações da educação formal } \\
\text { com a não formal. } \\
\text { Proposições aos estudantes para enviarem as dúvidas por } \\
\text { meio do Mural da Sala de Aula de modo síncrono, sobre o } \\
\text { funcionamento das aulas remotas e sobre os conteúdos } \\
\text { trabalhados nas aulas presenciais. } \\
\text { Tarefa extra: produção individual do resumo e do } \\
\text { fichamento do livro de Gohn, Educação Não-formal e } \\
\text { Cultura Política: impactos sobre o associativismo do 3o } \\
\text { Setor São Paulo: Cortez, 2011, conforme orientações } \\
\text { enviadas pela professora por meio da Sala de Aula. }\end{array}$ \\
\hline $\begin{array}{l}\text { Compreensão/ } \\
\text { Interpretação }\end{array}$ & & $\begin{array}{l}\text { Esclarecimento de dúvidas por meio do Skype, sobre } \\
\text { ensino remoto e destaque aos compromissos na } \\
\text { manutenção da qualidade do ensino e da necessidade de } \\
\text { responsabilidade dos estudantes na aprendizagem. } \\
\text { Definição das estratégias de comunicação síncrona } \\
\text { (compromisso de participar das videoconferências, nos } \\
\text { dias e horários da disciplina) e assíncrona (devolutiva das } \\
\text { atividades na Sala de Aula, envio de mensagens por meio } \\
\text { de e-mail para esclarecimentos de dúvidas e/ou pelo } \\
\text { WhatsApp). } \\
\text { Explicações sobre como acessar a Sala de Aula, o Plano de } \\
\text { Ensino, os conteúdos, os vídeos, os filmes e as atividades. }\end{array}$ \\
\hline
\end{tabular}




\begin{tabular}{|c|c|c|}
\hline Análise/Crítica & $\begin{array}{l}\text { A16 a A19 } \\
\text { Pedagogia ao longo } \\
\text { da história. }\end{array}$ & $\begin{array}{l}\text { Acolhimento da turma; apresentação dos objetivos da } \\
\text { aula; levantamento dos conhecimentos prévios dos } \\
\text { estudantes sobre a Pedagogia ao longo da história e a } \\
\text { formação do pedagogo. } \\
\text { Exposição didática dialogada; comparação de concepções } \\
\text { de diferentes autores; discussão sobre a formação do } \\
\text { pedagogo segundo a LDBEN e as Diretrizes Curriculares } \\
\text { Nacionais (DCNs). } \\
\text { Tarefa extra: pesquisa de referenciais teóricos sobre a } \\
\text { atuação do pedagogo em espaços não escolares. } \\
\text { Envio pela professora, em horários extras, de devolutiva } \\
\text { dos resumos e fichamentos individuais, assinalando os } \\
\text { pontos para os estudantes reelaborarem mais atividades. }\end{array}$ \\
\hline $\begin{array}{l}\text { Obtenção e } \\
\text { organização dos } \\
\text { dados. }\end{array}$ & $\begin{array}{l}\text { A20 a A34 } \\
\text { O Pedagogo em } \\
\text { órgãos de } \\
\text { Planejamento } \\
\text { Educacional; nos } \\
\text { Museus; nas } \\
\text { Câmaras Municipais; } \\
\text { na Promotoria de } \\
\text { Justiça e de Defesa } \\
\text { da Educação. } \\
\text { A Pedagogia Agrária. } \\
\text { A Pedagogia nos } \\
\text { Presídios e } \\
\text { delegacia; nos } \\
\text { meios de } \\
\text { comunicação e no } \\
\text { turismo. }\end{array}$ & $\begin{array}{l}\text { Apresentação pelos estudantes das pesquisas realizadas, } \\
\text { mediadas por questionamentos da professora. } \\
\text { Exposição didática dialogada por meio de slides e exibição } \\
\text { de vídeos. } \\
\text { Apresentação da professora das situações de atuação do } \\
\text { pedagogo nas instituições públicas e empresas; e } \\
\text { promoção da discussão na turma. Apresentação de } \\
\text { conclusões. } \\
\text { Tarefa extra: resolução de questionário. Prova agendada. } \\
\text { Realização da prova no sistema durante as horas/aula } \\
\text { destinadas às A32, A33 e A34. }\end{array}$ \\
\hline
\end{tabular}

Quadro 2 - Operação mental, textos e atividades desenvolvidos nas aulas remotas, iniciadas no dia 12 de março de 2020

Fonte: elaborado pela autora (2020). 


\begin{tabular}{|c|c|c|}
\hline Operação Mental & $\begin{array}{l}\text { № de Aulas/ } \\
\text { Conteúdos }\end{array}$ & Atividades propostas para os estudantes \\
\hline Crítica & $\begin{array}{l}\text { A } 35 \text { a A37 } \\
\text { Revisão dos } \\
\text { Conteúdos e } \\
\text { atividades da } \\
\text { Unidade I. }\end{array}$ & $\begin{array}{l}\text { Promoção de discussão pela professora acerca das } \\
\text { respostas dos estudantes nas provas e dos resultados } \\
\text { obtidos nas avaliações formativas e somativas. } \\
\text { Avaliação dos estudantes acerca das videoconferências, } \\
\text { atividades e aprendizagens da Unidade I. } \\
\text { Tarefa extra: leitura dos textos "Pedagogia Social" e } \\
\text { "Pedagogia Social de Rua", de Graciane (2005) e Caliman } \\
\text { (2020). }\end{array}$ \\
\hline $\begin{array}{l}\text { Levantamento de } \\
\text { hipóteses/análises }\end{array}$ & $\begin{array}{l}\text { A38 a A43 } \\
\text { Pedagogia Social; } \\
\text { A Pedagogia Social de } \\
\text { Rua. }\end{array}$ & $\begin{array}{l}\text { Acolhida e solicitação aos estudantes de exposição das } \\
\text { ideias principais dos textos atribuídos para leitura na aula } \\
\text { anterior, mediados por questionamentos da professora } \\
\text { previamente planejados. } \\
\text { Exposição didática dialogada por meio de slides, } \\
\text { entremeada com exibição de vídeos, seguida de } \\
\text { atividades e discussão em grupo. } \\
\text { Tarefa extra: pesquisa de práticas de Pedagogia Social } \\
\text { desenvolvidas no Brasil. Solicitação aos estudantes para } \\
\text { que pensassem e descrevessem uma possível prática de } \\
\text { pedagogia social. } \\
\text { Acolhida, seguida de solicitação aos estudantes da } \\
\text { apresentação das pesquisas e da prática de pedagogia } \\
\text { social, mediadas por questionamentos da professora, e } \\
\text { discussão no grupo. } \\
\text { Tarefa extra: leitura e destaque das ideias centrais do } \\
\text { artigo "O Pedagogo na Empresa” (PASCOAL, 2007). }\end{array}$ \\
\hline $\begin{array}{l}\text { Compreensão/ } \\
\text { Interpretação/ } \\
\text { Análise/Síntese }\end{array}$ & $\begin{array}{l}\text { A44 a A49 } \\
\text { Pedagogo na } \\
\text { Empresa. }\end{array}$ & $\begin{array}{l}\text { Acolhida dos estudantes. Solicitação aos estudantes para } \\
\text { que partilhassem os pontos considerados relevantes no } \\
\text { artigo "Pedagogia na Empresa". } \\
\text { Exposição didática dialogada do conteúdo com uso de } \\
\text { slides, entremeada por questionamentos da professora e } \\
\text { dos estudantes. } \\
\text { Tarefa extra: visionamento do filme } O \text { amor é } \\
\text { contagioso, com anotações dos pontos que envolvem } \\
\text { educação, saúde e atendimento hospitalar humanizado. }\end{array}$ \\
\hline
\end{tabular}




\begin{tabular}{|c|c|c|}
\hline $\begin{array}{l}\text { Aplicação de fatos e } \\
\text { princípios a novas } \\
\text { situações/Decisão/ } \\
\text { Planejamento de } \\
\text { Projetos e Pesquisas }\end{array}$ & $\begin{array}{l}\text { A50 a A70 } \\
\text { A Pedagogia } \\
\text { Hospitalar no } \\
\text { contexto do curso de } \\
\text { Pedagogia. } \\
\text { O porquê da } \\
\text { denominação } \\
\text { "Pedagogia } \\
\text { Hospitalar". } \\
\text { A } \\
\text { multi/inter/transdici- } \\
\text { plinaridade e a } \\
\text { Pedagogia Hospitalar. } \\
\text { A prática pedagógica } \\
\text { em contexto } \\
\text { hospitalar/ONGs. }\end{array}$ & $\begin{array}{l}\text { Apresentação das análises do filme pelos estudantes, } \\
\text { seguida de questionamentos da professora. } \\
\text { Exposição didática dialogada das relações educação e } \\
\text { saúde. } \\
\text { Tarefa extra: leitura do livro de Silva e Andrade, } \\
\text { Pedagogia Hospitalar: fundamentos e práticas de } \\
\text { humanização e cuidado. Editora UFRB, Cruz das Almas. } \\
\text { 2013. } \\
\text { Partilha dos estudantes das ideias centrais do livro e das } \\
\text { dificuldades de compreensão. } \\
\text { Exposição didática dialogada acerca dos conteúdos. } \\
\text { Resolução de situações-problema sobre Pedagogia } \\
\text { Hospitalar e das articulações Pedagogia Hospitalar e } \\
\text { Pedagogia Social. } \\
\text { Tarefa extra: visionamento do filme Estamira, com } \\
\text { orientações para reflexões acerca das pessoas com } \\
\text { deficiências, com doenças mentais e da educação. } \\
\text { Apresentação e debate em sala de aula. } \\
\text { Tarefa extra: solicitação aos estudantes para que, em } \\
\text { grupo de no máximo três estudantes, analisassem o seu } \\
\text { entorno e pensassem em um problema relacionado aos } \\
\text { conteúdos estudados na disciplina para apresentação do } \\
\text { tema-problema e dos objetivos na aula seguinte. } \\
\text { Apresentação dos temas-problema e objetivos pelos } \\
\text { grupos, seguida de orientações da professora para } \\
\text { possível reelaboração. } \\
\text { Orientações para elaboração dos projetos de intervenção } \\
\text { em espaços não escolares nas videoconferências e de } \\
\text { forma assíncrona. } \\
\text { Encaminhamento do roteiro do projeto. } \\
\text { Encaminhamento pelos estudantes dos projetos, por } \\
\text { meio de e-mails para análises e reelaborações. } \\
\text { Estabelecimento de horários para plantão de dúvidas. } \\
\text { Postagem pelos estudantes dos projetos no Google } \\
\text { Classroom. } \\
\text { Apresentação pelos grupos de estudantes dos projetos } \\
\text { de intervenção em espaços não escolares nasciplina e entrega dos resultados finais. } \\
\text { Pideonferência, seguida de discussões. }\end{array}$ \\
\hline
\end{tabular}

Quadro 3 - Operação mental, textos e atividades desenvolvidos nas aulas remotas da Unidade II Fonte: elaborado pela autora (2020). 


\section{ENSINO, APRENDIZAGEM E AVALIAÇÃO: EXPERIÊNCIAS DA TRANSIÇÃO DO ENSINO PRESENCIAL PARA O REMOTO}

Esta seção está organizada em três etapas: na primeira tratar-se-á dos conteúdos e estratégias de ensino e aprendizagem; na segunda serão discutidos os instrumentos de avaliação da aprendizagem; e na terceira serão expostas as reflexões acerca da participação efetiva dos estudantes e dos problemas enfrentados durante as aulas, evidenciados por meio de relatos de quatro estudantes, denominados de E1, E2, E3 e E4.

A transição do ensino presencial para as aulas remotas fora realizada de forma abrupta, logo, foi preciso encontrar tempo para a autoformação nas TDIC. Nesse período, a professora realizou a leitura de artigos científicos e tutoriais; visualizou vídeos de aulas de professores da USP, da UNESP e da UFSCar; discutiu e esclareceu dúvidas com colegas de trabalho; e fez simulações de aulas experimentais. O objetivo foi melhorar a sua fluência digital, aspecto relevante para aulas remotas. Os estudantes precisaram de leituras de tutoriais, visualização de vídeos e, principalmente, da adaptação às aulas por meio de videoconferências, com a demonstração de corresponsabilidade na sua formação. Desse modo, como citado anteriormente, foram transferidos os conteúdos e as atividades postados na sala de aula experimental e concretizaram-se as unidades de aprendizagem na sala de aula oficial, com a utilização do Google Meet para realizar videoconferências, agendadas previamente.

A professora pautou o seu trabalho na direção da progressão cognitiva do conhecimento, inspirada no método dialético e no modelo de ensino híbrido, por isso, no primeiro encontro virtual, discutiu a continuidade da sua proposta de trabalho apresentada presencialmente, na busca de compartilhar as responsabilidades mediante recomendações quanto ao cumprimento dos horários das aulas, o envolvimento dos alunos nos estudos nas Unidades de Aprendizagem e nas comunicações (Mural do Google Classroom, WhatsApp, E-mail), a participação com câmeras ligadas, quando possível, durante as videoconferências e a interlocução por microfone e chat. Explicou que a avaliação seria on-line, por meio de atividades síncronas e assíncronas, deixando clara a priorização do ensino remoto sobre a educação a distância, com ênfase no compromisso de considerar as singularidades, dificuldades e heterogeneidade dos estudantes.

Quanto aos conceitos de educação a distância, esses evoluem conjuntamente com avanços das TDIC, sendo constantemente modificados por nós professores e pelos alunos, num processo de aprendizagem contínuo, tendo em vista que:

o presencial se virtualiza e a distância se presencializa. Os encontros em um mesmo espaço físico se combinam com os encontros virtuais, à distância, através da Internet. E a educação a distância cada vez aproxima mais as pessoas, pelas conexões on-line, em tempo real, que permite que 
professores e alunos falem entre si e possam formar pequenas comunidades de aprendizagem (MORAN, 2003, p. 1).

Como previsto pelo autor, com a utilização de recursos da internet, aulas estão sendo ministradas de forma on-line, de um modo presencial não físico, no qual professores e alunos interagem entre si, de modo síncrono, de forma que todos veem uns aos outros por meio do Google Meet. Esse modo é denominado, neste trabalho, como processo de aprendizagem remoto.

Anastasiou e Alves (2015, p. 30) argumentam que os processos de ensinagem no ensino superior devem se constituir em espaços de ensino fundamentados na lógica dialética, composta por momentos de mobilização, visão inicial (sincrética), construção do conhecimento (antítese) e construção e elaboração da síntese do conhecimento. Para as autoras, na dialética, o conhecimento passa por uma afirmação inicial, depois se constrói a contradição (antítese) para se chegar a uma nova visão (síntese).

Ainda no que diz respeito à dialética, Freire (2010, p. 136) afirma que "o professor não deve poupar oportunidade para testemunhar aos alunos, a segurança que se comporta para discutir um tema, analisar um fato". Assim, ele deve se posicionar frente à razão ética, o seu fundamento político, a sua referência pedagógica, numa relação dialógica com a realidade dos estudantes para desafiá-los à inquietação, curiosidade e inconclusão permanente.

$\mathrm{Na}$ esteira desses entendimentos e com base nas intencionalidades da disciplina, com foco no desenvolvimento das operações do pensamento descritas por Raths et al. (1977 apud ANASTASIOU; ALVES, 2015, p. 33), as videoconferências foram subdividas em três momentos: mobilização (leitura de textos reflexivos para acolhimento e/ou conversa informal); levantamento do conhecimento prévio e/ou ideia inicial do conteúdo; e exposição didática dialogada com o compartilhamento de slides, vídeos e documentários. Tudo isso com vistas à efetivação da análise (aprofundamento), na busca de uma síntese (apropriação), realizada por meio das discussões em grupo nas videoconferências e nas atividades formativas e somativas, tais como: desafios de aprendizagem, estudos de caso, resumos e fichamentos de livros, elaboração e apresentação de projetos de intervenção, simulação e/ou apresentação de situações reais, quizzes e provas bimestrais. Essa metodologia é denominada de sala de aula invertida (flipped classroom), considerada modelo inovador de ensinar, porque disponibiliza as informações básicas no ambiente virtual e deixa a sala de aula para provocar situações, demonstrar e discutir realidades, desafiar a pensar em intervir em problemas que afetam a vida das pessoas, incentivando o estudante à corresponsabilidade quanto ao desenvolvimento cognitivo.

Nesse modelo, Moran aponta, em uma entrevista ao Correio Brasiliense (2014), que o papel do professor é mais curador do que orientador: curador quando escolhe os conteúdos e as atividades consideradas essenciais para o progresso cognitivo dos estudantes, com 
acolhimento, seriedade, apoio e disponibilização; orientador na medida em que oferece os feedbacks direcionados com comentários, análises das produções individuais e/ou dos grupos com indicação das melhorias no trabalho, durante e no fim do processo de ensino e aprendizagem.

É importante destacar que os desafios da educação dialógica alinhada aos preceitos da sala de aula invertida estiveram presentes nos três momentos, pois ocasionaram significativas interações entre a professora e os estudantes e entre os estudantes. A maioria, antes das aulas, leu os textos propostos, assistiu os vídeos, filmes, realizou os desafios de aprendizagem e, durante as aulas, participou ativamente, dirigiu questionamentos à professora para esclarecer dúvidas acerca dos novos conceitos e/ou atividades propostas, emitiu posicionamentos e não faltou às aulas, obtendo $100 \%$ de frequência. Nas videoconferências, dos 31 estudantes matriculados na disciplina, participavam em torno de 19, 20 e 23 estudantes, raramente 31 . Os estudantes faltosos justificavam suas ausências com os argumentos de problemas de conexão com a internet, então acessavam os conteúdos postados no Google Classroom e, por meio do WhatsApp ou E-mail, solicitavam explicações e/ou esclarecimento de dúvidas à professora, estratégia que contribuiu para que todos fossem aprovados. Quanto ao envolvimento da turma nos debates durante as videoconferências, em alguns dias o intervalo foi esquecido, ficando por três horas seguidamente.

Além disso, também é imperioso ressaltar que, para desenvolver operações mentais com progressivos níveis de complexidade (expressas nos quadros 1, 2 e 3), os estudantes devem assumir de forma proativa a sua aprendizagem, realizando as tarefas propostas antes das aulas. Para tanto, o pensamento deixa a passividade e passa a inferir para sustentar posicionamentos. Essa postura converte os paradigmas cristalizados nos conceitos de ensino e aprendizagem e passam a compreendê-los como processos da interconexão entre as concepções individuais dos estudantes, as dos autores estudados e as do professor, em um ato de construção e reconstrução do conhecimento centrado no aluno, defendido por teóricos como Dewey (1959), Freire (2010), Ausubel e Novark (apud MOREIRA, 1999), entre outros.

Com referência à passagem da passividade dos estudantes para a atividade, alguns resistem a esse modelo, já que esses foram acostumados a assistirem aulas de forma passiva, memorizar os conteúdos e realizar as atividades e provas; resquícios do ensino tradicional, centrado no professor, fonte principal de informação e conhecimento.

Esse problema acontecia durante as aulas presenciais e também ocorreu nas aulas remotas. Trata-se de estudantes que, apesar da tentativa da professora de mobilizá-los, instigá-los, por meio da problematização dos temas, de realidades, da solicitação de leitura prévia dos textos, realização de atividades, da visualização de filmes e vídeos para aprofundamento de 
temáticas em sala de aula, não conseguiram interagir nas aulas, correspondendo a cerca de $15 \%$ da turma. Talvez essa atitude se deva à não realização da tarefa extra e/ou ao fato de os estudantes não terem internalizado a importância do seu comprometimento com a sua aprendizagem. Além disso, normalmente, quando solicitados a pensar em um conceito ou analisar um problema, eles realizam tais atividades com base no senso comum. A professora pode, ainda, encontrar as estratégias pedagógicas que favoreçam motivações mais estimulantes para o envolvimento do aluno na aprendizagem. Isso demanda investimento das instituições de ensino no processo de formação continuada dos professores. A autoaprendizagem por si só não dá conta das constantes necessidades de aprimoramento profissional, face aos avanços das TDIC.

Juntamente a esses problemas, nesse período, alguns estudantes não participaram ativamente das videoconferências nas três horas/aula todos os dias por problemas de conexão com a internet. Alguns desses faziam leitura do material no Google Classroom e enviavam suas dúvidas para o Mural da Sala de Aula, WhatsApp ou E-mail, recebendo o feedback da professora.

Já em relação às atividades avaliativas encaminhadas, os estudantes demonstraram satisfação, porque a professora enviava observações com orientações para a melhoria da qualidade das atividades e consequentemente das suas notas. Vale frisar, ainda, que a maioria reelaborou suas atividades e obteve o feedback por mais de duas vezes. Isso exigiu mais tempo e disponibilidade da professora, situação que precisa ser reconhecida e remunerada pelas instituições de ensino superior. Assim, considera-se essencial, no ensino superior, o aluno se apropriar da elaboração de fichamentos de livros e textos, resumos, resenhas, análises de filmes, mapas mentais, mapas conceituais, produção de projetos de pesquisa e de intervenção, realização de trabalhos em grupos e apresentações, pois essas atividades ajudam os estudantes na obtenção de uma sólida formação acadêmica.

Com relação aos conteúdos da disciplina, os estudantes que não faltaram às aulas reconheceram que não tiveram prejuízos cognitivos e que houve crescimento intelectual e pessoal. Muitos sinalizaram positivamente, mas relataram a falta que faz o aconchego social, a troca dos olhares próximos e a atenção e o carinho da professora nas aulas presenciais. Nessa oportunidade, a professora agradeceu o empenho, compartilhou o sentimento da falta da energia do contato físico, parabenizou pelo compromisso de todos com a sua formação e finalizou com a leitura do poema "A falta que a falta faz" do livro A parte que falta, de Shel Silverstein (2018), fazendo, assim, o exercício da reflexão a partir da própria ação.

No que diz respeito à avaliação da aprendizagem, essa foi realizada processual e continuamente, de forma síncrona e assíncrona, com o objetivo de garantir as progressivas aprendizagens. Obtiveram-se resultados positivos, todos os estudantes conseguiram a 
aprovação e na última aula foi solicitado que socializassem as impressões, os comentários e as críticas acerca do desenvolvimento da disciplina na perspectiva de melhoria, que estão representados pelos depoimentos desses quatro estudantes que apresentaram pontos similares às análises dos demais colegas.

"Foi uma excelente experiência com a disciplina 'Educação em Espaços não Escolares', visto que através das aulas e materiais foi possivel conhecer campos da Pedagogia antes não imaginados, levando a uma profunda reflexão da educação e da atuação Pedagógica" (E1).

"Foi muito importante aprender novos conhecimentos a respeito de trabalhar fora da escola, em espaços não escolares, o aproveitamento do conteúdo irá ajudar o profissional entender como funciona esse trabalho externo. Diante do que aprendi irá ser um acréscimo na hora de partir para a prática nos projetos que irão serem realizados para melhorar a comunidade que está passando por problemas educacionais. $O$ que nos foi ensinado foi muito completo e não restou dúvidas para possíveis melhorias, a troca de conhecimento entre nós discente e docente nos ajudou a entender o que é uma educação em espaços não escolares" (E2).

"Toda a estrutura e conteúdo do planejamento, foram muito bem elaborados e muito bem trabalhados. Mesmo com o distanciamento social, foi possivel aprender através do diálogo por meio dos encontros online, assim tirando as dúvidas e podendo fazer parte de forma direta do nosso processo de aprendizagem" (E3).

"Embora aconteceu alguns momentos de dificuldade devido aos problemas de conexão, é fato, que a tecnologia deve ser mais usada por todos nos currículos escolares. A professora, como sempre apresentou de forma clara e objetiva os conteúdos, sempre disposta a eliminar quaisquer dúvidas que dificultasse o entendimento, além disso, os dispositivos disponibilizados em sala estava numa linguagem clara, servindo até para outras disciplinas. Não senti dificuldade em minha aprovação, mesmo não participando cem por cento dos encontros" (E4).

Esses depoimentos reverberam reflexões acerca da importância dos saberes construídos a partir dessa experiência. As aulas remotas, em tempos de pandemia, se constituíram em uma experiência docente mais humana, pois, além das preocupações de garantir qualidade nas aprendizagens e autoformação, a professora precisou proporcionar equidade no acesso ao conhecimento, principalmente aos alunos que não demonstraram condições digitais de acompanhar as videoconferências.

\section{CONSIDERAÇÕES FINAIS}

Num cenário de pandemia, pode-se inferir que as aulas remotas se tornaram alternativas viáveis para a continuidade dos estudos. Na disciplina relatada, houve tentativa de replicar as atividades das aulas presenciais nas aulas remotas, porém houve delimitações - 
ocasionadas pelas dificuldades de conexão com a internet de alguns alunos -, de atentar fisicamente para cada dificuldade e, sobretudo, de realizar as atividades práticas, devido ao perigo de contaminação da COVID-19.

Com relação ao conteúdo que foi ensinado, os estudantes tiveram acesso aos saberes curriculares considerados fundamentais, planejados pela disciplina para a formação do pedagogo, não havendo prejuízos cognitivos.

No que diz respeito às estratégias de ensino e aprendizagem, as videoconferências gravadas, mediadas pela apresentação de slides, de forma dialógica, induziram os estudantes a refletirem sobre suas concepções e/ou interpretações prévias e a confrontarem com as ideias dos autores dos textos estudados, numa intercomunicação síncrona e assíncrona da professora com os estudantes. Como citado anteriormente, pela prevenção da propagação do novo coronavírus, não foi possível realizar pesquisas em espaços não escolares com vistas a dialogar com o contexto cultural, aplicar os projetos de intervenção em instituições não escolares, produzir vídeos e apresentações da experiência, por meio de socialização, para divulgação dos resultados. Os projetos realizados e apresentados pelos estudantes desenrolaram-se em caráter de simulações de realidades.

No tocante às atividades de avaliação da aprendizagem, os estudantes tiveram orientações para a realização das atividades formativas e submeteram seus resumos, fichamentos, questionários e projetos à análise, avaliação e reavaliação pela professora. As provas presenciais foram substituídas por provas on-line e obtiveram resultados positivos.

Por fim, as práticas pedagógicas apresentadas requereram da professora autoformação nas TDIC para se reconstruir em um período de adaptação a uma nova realidade não dimensionada. Os estudantes desempenharam um papel ativo e dinâmico frente aos desafios que lhes foram apresentados durante o semestre letivo. Com isso, tendo em vista que "é pensando criticamente a prática de hoje ou de ontem que se pode melhorar a próxima prática" (FREIRE, 2010, p. 39), acredita-se que a publicização de reflexões das experiências vivenciadas no ensino remoto, atrelada a uma sólida formação nas TDIC, poderá contribuir para o aprimoramento dos processos de ensinagem. Isso uma vez que as limitações da professora no tocante à utilização ampla das TDIC ensejaram reflexões para a melhoria das práticas futuras.

\section{REFERÊNCIAS}

ALMEIDA, Maria Elizabeth Biancocini de; VALENTE, José Armando. Integração currículo e as tecnologias e a produção de narrativas digitais. Currículo sem Fronteiras, v. 12, n. 3, p. 57-82, set./dez. 2012. Disponível em: http://www.waltenomartins.com.br/pmd_aula1_art01.pdf. Acesso em: 10 mar. 2020. 
ANASTASIOU, Lea das Graças Camargo; ALVES, Leobir Passate. (org.). Processo de Ensinagem na Universidade: pressupostos para estratégia de trabalho em aula. 10. ed. Santa Catarina: Editora UNIVILLE, 2015. Disponível em:

https://edisciplinas.usp.br/pluginfile.php/4101112/mod_resource/content/1/Anastasiou_Al ves_ProcessosdeEnsinagem.pdf. Acesso em: 2 mar. 2017.

BASTOS, Celso da Cunha. Metodologias Ativas. 2006. Disponível em:

http://educacaoemedicina.blogspot.com.br/2006/02/metodologias-ativas.html. Acesso em: 10 abr. 2020.

BRASIL. Resolução CNE/CP no 1/2006. Institui Diretrizes Curriculares Nacionais para o Curso de Graduação em Pedagogia, licenciatura. Conselho Nacional de Educação Conselho Pleno (CNE/CP). Brasília, 2006. Disponível em:

http://portal.mec.gov.br/cne/arquivos/pdf/rcp01_06.pdf. Acesso em: 23 nov. 2015.

BRASIL. Ministério da Educação. Portaria no 343/2020. Dispõe sobre a substituição das aulas presenciais por aulas em meios digitais enquanto durar a situação de pandemia do Novo Coronavírus - COVID-19. Diário Oficial da União, Brasília, 18 março 2020. Disponível em: https://www.in.gov.br/en/web/dou/-/portaria-n-343-de-17-de-marco-de-2020-248564376. Acesso em: 20 mar. 2020.

DEWEY, John. Vida e Educação. São Paulo: Nacional, 1959.

FREIRE, Paulo. Pedagogia da autonomia: saberes necessários à prática educativa. São Paulo: Paz e Terra, 2010.

LÉVY, Pierre. Cibercultura. São Paulo: Editora 34, 1999.

MORAN, José Manuel. Ensino e Aprendizagem inovadores com tecnologias auditivas e temáticas. In: MORAN, José Manuel; MASETTO, Marcos. T; BEHRENS, Marilda Aparecida. As novas tecnologias e mediação pedagógica. São Paulo: Papirus, 2000.

MORAN, José Manuel. Educação inovadora presencial e a distância. 2003. Disponível em: http://www.eca.usp.br/prof/moran/site/textos/tecnologias_eduacacao/inov.pdf. Acesso em: 5 abr. 2020.

MORAN, José Manuel. Metodologias ativas e modelos híbridos de educação. 2018.

Disponível em:

http://www2.eca.usp.br/moran/wpcontent/uploads/2018/03/Metodologias_Ativas.pdf. Acesso em: 5 mar. 2020.

MORAN, José Manuel et al. Novas tecnologias e mediação pedagógica. 13. ed. Campinas: Papirus, 2007.

CORREIO BRASILIENSE. Entrevista José Manuel Moran. Brasília, 2014. Disponível em: http://www2.eca.usp.br/moran/wp-content/uploads/2014/01/Jos\%C3\%A9-Moran.pdf. Acesso em: 5 mar. 2020. 
MOREIRA, Marco Antônio. Teorias de Aprendizagem. São Paulo: Editora Pedagógica e Universitária Ltda, 1999.

RATHS, Louis E. et al. Ensinar a pensar. 2. ed., São Paulo: EPU, 1977.

SILVERSTEIN, Shel. A Parte que Falta. São Paulo: Companhia das Letrinhas, 2018.

TARDIF, Maurice; LESSARD, Claude. O trabalho professora: elementos para uma teoria da docência como profissão das interações humanas. 6. ed. Petrópolis: Vozes, 2011.

\section{Maria Claudice Rocha Almeida}

Mestra em Educação (Universidade Federal de Sergipe). Licenciada em Pedagogia. Especialista em Mídias na Educação, Psicopedagogia Clinica e Institucional, Gestão e Planejamento Escolar. Atua como professora e coordenadora do NAPP na Faculdade Dom Pedro II de Sergipe. Assessora Técnica do Conselho Municipal de Educação de Lagarto. Estuda e pesquisa formação de professores e saberes docentes.

maria.almeida@unidompedro.com 